\title{
Controle Tecnológico do Concreto de Cimento Portland - Estudo de Caso
}

\author{
Cristiane Carine dos Santos ${ }^{1 *}$, Marina Munaretto Copetti ${ }^{2}$, Tássia Fanton ${ }^{3}$ \\ cristiane.c.santos@ufsm.br \\ ${ }^{1}$ Departamento de Engenharia Sanitária e Ambiental, Universidade Federal de Santa Maria, Santa Maria, Brasil \\ ${ }^{2}$ Secretaria Acadêmica, Universidade Federal de Santa Maria, Cachoeira do Sul, Brasil \\ ${ }^{3}$ Programa de Pós-Graduação em Engenharia Civil, Universidade Federal de Santa Maria, Santa Maira, Brasil.
}

\begin{abstract}
RESUMO
O controle tecnológico do concreto em conformidade com a NBR 12655:2015 possui um papel fundamental no desempenho, durabilidade e segurança das edificações. Controle este, apesar da sua importância vem sendo negligenciado em obras na cidade de Frederico Westphalen, conforme pode ser verificado com a realização de quatro estudos de casos. Os ensaios exigidos para o recebimento e aceitação do concreto foram adotados pela primeira vez no desenvolvimento desta pesquisa, onde pode-se observar a ocorrência de desconformidades nos valores de abatimento de alguns caminhões, a redução de 7,45\% do fck, estm dos corpos de prova submetidos a mesma cura da obra quando comparados aos curados em laboratório, como outras desconformidades com as normas NBR 7212:2012 e NBR 12655:2015 durante as concretagens.
\end{abstract}

Palavras- chave: concreto; aceitação; consistência; resistência; controle tecnológico.

\section{INTRODUÇÃO}

Atualmente o concreto juntamente com o aço, constitui o que se entende por concreto estrutural, armado ou protendido. Caracteriza-se como um produto líder para uso estrutural nas construções, 
devido ao conjunto desses materiais resistirem simultaneamente a esforços de tração e compressão, possibilitando a construção de estruturas com maiores vãos e alturas.

Mehta e Monteiro (2014) estimam que o consumo de concreto no mundo seja na ordem de 19 bilhões de toneladas métricas ao ano. Embora ele não seja tão duro e resistente quanto o aço seu consumo superior é justificado pelo menos por três razões principais: a primeira é a excelente resistência do concreto à água; a segunda razão é a facilidade com a qual ele se adapta a diferentes formas e tamanhos, devido a sua consistência plástica no estado fresco que favorece o fluxo do material para o interior das formas; e a terceira justificativa é o seu baixo custo e a rápida disponibilidade do material.

Segundo Neville (2013), enquanto o aço é produzido sob condições rigidamente controladas, com as propriedades de cada tipo de aço determinadas em laboratório e apresentadas no certificado do fabricante, cabendo aos projetistas da estrutura somente especificá-lo, e ao construtor garantir que o aço correto seja usado e que as conexões entre os elementos sejam efetuadas de maneira adequada. O controle tecnológico do concreto é mais complexo pois a garantia de sua qualidade depende das propriedades de cada um dos materiais componentes e os fatores que podem alterálas, dosagem correta e execução cuidadosa da mistura, transporte, lançamento e a cura adequada até o endurecimento.

O controle tecnológico do concreto tem como objetivo garantir que este esteja de acordo com os parâmetros estabelecidos pelas normas e necessários para a perfeita execução das obras e consequente durabilidade da estrutura.

A "NBR 12655:2015 - Concreto de Cimento Portland - Preparo controle, recebimento e aceitação - Procedimento" estabelece diretrizes e ações a serem tomadas para garantir que o controle tecnológico seja realizado de forma eficiente.

Dentre essas diretrizes estabelecidas estão as responsabilidades de cada um dos profissionais envolvidos, a execução da rastreabilidade do concreto lançado na estrutura e realização dos ensaios de consistência e resistência à compressão axial ao menos aos 28 dias, para recebimento e aceitação do concreto.

No entanto, na realidade de muitas obras o controle tecnológico do concreto não ocorre de maneira satisfatória, conforme estabelecido pela norma. Em alguns casos o concreto dosado em central tem a sua resistência verificada apenas pelas empresas fornecedoras, sem a conferência por parte dos proprietários e responsáveis técnicos das obras se as características solicitadas do concreto estão realmente sendo atendidas.

Portanto, o presente trabalho foi realizado com intuito de verificar qual é o controle tecnológico empregado nas obras da cidade de Frederico Westphalen, já que esse desempenha um papel imprescindível na qualidade, desempenho e segurança das obras.

\section{CONTROLE TECNOLÓGICO DO CONCRETO}

Para Bauer (2017) o controle tecnológico do concreto é um processo aplicado nas obras de concreto armado, protendido ou pré-fabricado que visa o registro e a garantia da conformidade dos concretos empregados, com base nas especificações técnicas do projeto estrutural ou de outros documentos técnicos.

Desta maneira o controle tecnológico do concreto regido pela NBR 12655:2015, visa a partir de procedimentos descritos pela norma, assegurar a qualidade e conformidade dos concretos empregados em obras, de maneira que estes atendam aos requisitos estabelecidos em seus projetos estruturais.

\subsection{Atribuições e responsabilidades de acordo com a NBR 12655:2015}


Segundo estabelece a norma cabem ao proprietário e o responsável técnico por ele designado garantir o seu cumprimento, bem como armazenar pelo prazo de 5 anos os documentos comprobatórios (laudos, relatórios de ensaios e etc).

As empresas fornecedoras dos serviços de concretagem cabem garantir o cumprimento das prescrições da norma NBR 12655:2015 relativas as etapas de preparo do concreto bem como as prescrições da NBR 7212:2021, devendo armazenar pelo prazo de 5 anos a documentação comprobatória.

Aos profissionais responsáveis pelo projeto estrutural cabem explicitar em todos os contratos, desenhos e memoriais que descrevem o projeto, a resistência característica à compressão do concreto $\left(f_{c k}\right)$; especificação da resistência característica à compressão do concreto a $\mathrm{j}$ dias $\left(\mathrm{f}_{\mathrm{ckj}}\right)$ para as etapas construtivas; especificação dos requisitos correspondentes à durabilidade da estrutura e elementos pré-moldados durante sua vida útil; especificação dos requisitos correspondentes às propriedades especiais do concreto durante a fase construtiva e vida útil da estrutura.

Já aos profissionais responsáveis pela execução da obra, cabem a escolha da modalidade de preparo; escolha do tipo de concreto a ser empregado, de acordo com as especificações de projeto e condições de aplicação; atendimento a todos os requisitos de projeto; recebimento e aceitação do concreto.

\subsection{Concreto dosado em central}

O tempo de transporte, conforme estabelece a NBR 7212:2021, deve ser inferior a 90 minutos e fixado de maneira que o fim da descarga seja de no máximo 150 minutos, contado a partir da primeira adição de água no caso de veículo dotado de equipamento de agitação e 40 minutos para veículo não dotado de equipamento de agitação; ficando assim, o tempo da descarga limitado em 60 minutos. O tempo de descarga pode ser flexibilizado segundo Neville (2016, p. 228) "com a utilização de retardadores de pega, o tempo máximo pode ser estendido para três ou até mesmo quatro horas, desde que seja garantido que a temperatura do concreto na entrega seja inferior a $32^{\circ} \mathrm{C}$."

\subsection{Ensaios realizados para aceitação do concreto}

A NBR 12655:2015 determina que para cada tipo de classe de concreto, os quais são classificados pela "NBR 8953:2015 - Concretos para fins estruturais - Classificação pela massa especifica, por grupos de resistência e consistência" conforme sua resistência e classe de consistência, além dos cuidados com a exposição da estrutura, conforme estabelece a "NBR 6118:2014 - Projeto de estruturas de concreto - Procedimento", devem ser realizados os ensaios de consistência regidos pela "NM 16889:2020 - Concreto — Determinação da consistência pelo abatimento do tronco de cone.

Determinação da consistência pelo abatimento do tronco de cone", para aceitação do concreto no estado fresco e ensaio de resistência à compressão, conforme a "NBR 5739:2018 - Concreto Ensaio de compressão de corpos de prova cilíndricos, para aceitação no estado endurecido".

\subsubsection{Ensaio de Consistência}

Segundo Anbrozewicz (2012), a consistência do concreto é uma propriedade relacionada com a fluidez da mistura, sendo fundamental para garantir a trabalhabilidade do concreto. 
Neville (2016) destaca que as propriedades do concreto endurecido são bastante afetadas pelo grau de adensamento, $5 \%$ de vazios podem diminuir em cerca de $30 \%$ a resistência final, sendo de vital importância o controle da trabalhabilidade ou consistência do concreto para que este seja adequadamente transportado, lançado, adensado e facilmente acabado, sem que ocorra a segregação.

\subsubsection{Ensaio de Resistência à Compressão Axial e Rastreabilidade do Lançamento do Concreto}

A NBR 12655:2015 estabelece que devem ser coletadas aleatoriamente amostras do concreto, de acordo com a "NM 33:1998 - Concreto - Amostragem de concreto fresco", durante a operação de concretagem para a realização do controle estatístico da resistência do concreto, o qual pode ser realizado por amostragem total ou por amostragem parcial.

As amostras devem ser coletadas aleatoriamente depois da última adição de água e completa homogeneização do concreto e dentro do intervalo de descarga de $15 \%$ e antes de completar a descarga de $85 \%$ do volume total da betonada

Cada exemplar de concreto deve ser constituído de dois corpos de prova, moldados conforme a "NBR 5738:2015 - Concreto - Procedimento para moldagem e cura de corpos de prova ", para cada idade de rompimento, tomando-se como resistência o maior valor dos dois valores no ensaio de resistência à compressão, realizado conforme a NBR 5739:2018.

\section{METODOLOGIA}

Para o desenvolvimento da pesquisa foram acompanhadas as concretagens de quatro obras na cidade de Frederico Westphalen, denominadas Obras A, B, C e D respectivamente, nas quais eram empregados concreto usinado fornecido por 2 empresas da cidade, denominadas respectivamente de Empresa X e Empresa Y. Tais nomenclaturas foram adotadas para evitar a exposição das obras e empresas, mantendo desta maneira o seu anonimato.

Primeiramente foi realizado o acompanhamento do recebimento do concreto dosado em central, verificando nas notas fiscais de todos os caminhões o horário de saída da central dosadora e horário de chegada no canteiro de obra, anotando-os posteriormente em uma planilha de controle, juntamente com o horário de início e fim de cada descarga. Tais dados foram coletados com o intuito de verificar se eram atendidos os aspectos exigidos pela NBR 7212:2021, como tempo máximo de deslocamento de 1,5 horas até o canteiro de obra e de 2,5 horas entre o intervalo da primeira adição de água até o lançamento do concreto.

Antes do início da descarga de todos os caminhões foi realizado o ensaio de abatimento de tronco de cone ("slump test"), seguindo as diretrizes da ABNT NM 16889:2020, para a verificação da consistência do concreto no estado fresco, analisando se este encontrava-se com trabalhabilidade adequada para seu lançamento nas formas ou se seu abatimento deveria ser corrigido com adição suplementar de água. Verificando também a aceitação ou rejeição do concreto no estado fresco, conforme determina a NBR 12655:2015.

Posteriormente foi acompanhado o início da concretagem aguardando a descarga de pelo menos $15 \%$ do volume total de concreto para a coleta das amostras dos concretos e antes da descarga de $85 \%$ do volume. As amostras foram coletadas no final da tubulação de bombeamento em uma única porção em um recipiente adequado.

Após a coleta, cuidando para que não fosse ultrapassado o tempo máximo de 15 minutos, foram moldados 4 corpos de prova para cada caminhão de concreto os quais, seguindo as diretrizes da NBR 5738:2015, foram moldados em moldes cilíndricos de aço com diâmetro de $100 \mathrm{~mm}$ e altura igual ao dobro do diâmetro devidamente revestidos interiormente por uma camada fina de óleo 
vegetal, sendo adensados manualmente em 2 camadas com o uso de uma haste metálica, aplicandose 12 golpes por camada.

Ao final da moldagem, os corpos de prova foram armazenados no local onde permaneceram pelo período de 24 horas, durante sua cura inicial. Sendo dois deles armazenados em local protegido das intempéries climáticas e os outros dois em local próximo a concretagem, recebendo as mesmas condições de exposição dos elementos concretados.

Durante o processo de concretagem foi realizada a rastreabilidade do concreto, de acordo com o estabelecido na NBR 12655:2015, onde, com o auxílio da planta de forma das lajes concretadas e de lápis de cores diferentes foram mapeados os locais onde foram lançados cada lote de concreto, possibilitando posteriormente, que em caso de falha na resistência de alguns dos lotes de concreto, saiba-se o local exato onde foram lançados.

Passadas 24 horas da concretagem, os corpos de prova que permaneceram expostos as intempéries climáticas, foram desmoldados e armazenados sobre as lajes concretadas, conforme ilustrado na Figura 3, recebendo a mesma cura e exposição dos elementos concretados por no mínimo 21 dias, sendo posteriormente levados ao laboratório onde foram submetidos ao ensaio de compressão axial. Os outros dois corpos de provas foram levados ao Laboratório de Materiais e Construção Civil - LMCC da URI, Campus de Frederico Westphalen logo após serem desmoldados, onde foram submetidos a cura em água saturada com cal a $(23 \pm 2){ }^{\circ} \mathrm{C}$ até o momento do ensaio.

Aos 28 dias de idade os corpos de prova foram submetidos ao ensaio e compressão axial, normatizado pela NBR 5739:2018, onde inicialmente a base e o topo dos corpos de prova foram retificados por desgaste mecânico, em máquina especialmente adaptada para a função. Posteriormente os corpos de prova foram posicionados adequadamente no equipamento de ensaio, onde foram submetidos a uma carga de compressão axial uniforme e sem choques, a uma velocidade fixada entre 0,3 a 0,8 MPa. Ao final, o valor da resistência foi obtido dividindo-se a carga de ruptura pela área transversal do corpo-de-prova.

Finalizado o ensaio de compressão axial, foi adotado o método de controle por amostragem total (100\%), especificado pela NBR 12655:2015. Onde o valor adotado como resistência característica a compressão axial de cada caminhão, foi o maior valor dentre os dois corpos de prova moldados. Posteriormente, os valores de f_(ck,est) do concretos curados em solução saturada de hidróxido de cálcio a $(23 \pm 2)^{\circ} \mathrm{C}, \mathrm{f} \_(\mathrm{ck}, \mathrm{est})$ dos concretos curados em obra e o f_ck de projeto foram comparados graficamente. Verificando se os valores de f_(ck,est) atendiam o valor de f_ck de projeto e dessa maneira, conforme a NBR 12655:2015 podiam ser aceitos ou deveriam ser rejeitados.

\section{RESULTADOS E DISCUSSÕES}

\subsection{Verificação das diretrizes da NBR 12655:2015}

Durante o acompanhamento da concretagem em todas as obras analisadas no presente trabalho, verificou-se que em nenhuma delas eram adotados os procedimentos preconizados pela NBR 12655:2015 para o recebimento e aceitação do concreto. Sendo a realização dos ensaios de consistência e compressão axial, previstos pela norma para o controle tecnológico dos concretos empregados, efetuados pela primeira vez com o desenvolvimento do presente trabalho.

Nota-se desta maneira, o descumprimento por parte do proprietário e responsável técnico da obra, no que diz respeito às suas atribuições e responsabilidades. Conforme estabelecido pela norma, cabem a eles as responsabilidades pela garantia de seu cumprimento, o recebimento e aceitação do concreto, armazenando pelo prazo de cinco anos toda documentação comprobatória da qualidade do concreto (relatórios de ensaios, laudos e outros).

\subsection{Coleta de dados e análise}




\section{Obra A}

$\mathrm{Na}$ obra A foram acompanhadas duas concretagens, a primeira no dia 05/06/2018 onde foi acompanhada a concretagem da laje do quarto andar e no dia 08/06/2018 a concretagens dos pilares deste mesmo andar, o concreto empregado foi fornecido pela empresa X. Nas respectivas datas foram coletados os dados demostrados na Tabela 1 e a rastreabilidade do lançamento dos concretos pode ser verificada na Figura 1.

Tabela 1. Dados Coletados na Obra A

\begin{tabular}{|c|c|c|c|c|}
\hline \multirow{4}{*}{ Informações Coletadas } & \multicolumn{4}{|c|}{ Data da Concretagem } \\
\hline & $05 / 06 /$ & & & $08 / 06 / 2018$ \\
\hline & \multicolumn{4}{|c|}{ Identificações dos Caminhões } \\
\hline & $\mathrm{C} 1$ & $\mathrm{C} 2$ & C3 & C1P \\
\hline Horário saída da central (horas: minutos) & $12: 39$ & $13: 37$ & $15: 18$ & 09:36 \\
\hline Horário chegada na obra (horas: minutos) & $13: 00$ & $14: 07$ & $15: 35$ & $10: 03$ \\
\hline Abatimento $(\mathrm{mm})$ & 175 & 145 & 120 & 80 \\
\hline Horário início da descarga (horas: minutos) & $13: 20$ & $14: 40$ & $15: 47$ & $10: 40$ \\
\hline Horário fim da descarga (horas: minutos) & $14: 40$ & $15: 40$ & $16: 30$ & $12: 30$ \\
\hline Adição de água (litros) & - & - & - & 50 \\
\hline Novo Abatimento (mm) & - & - & - & 140 \\
\hline
\end{tabular}

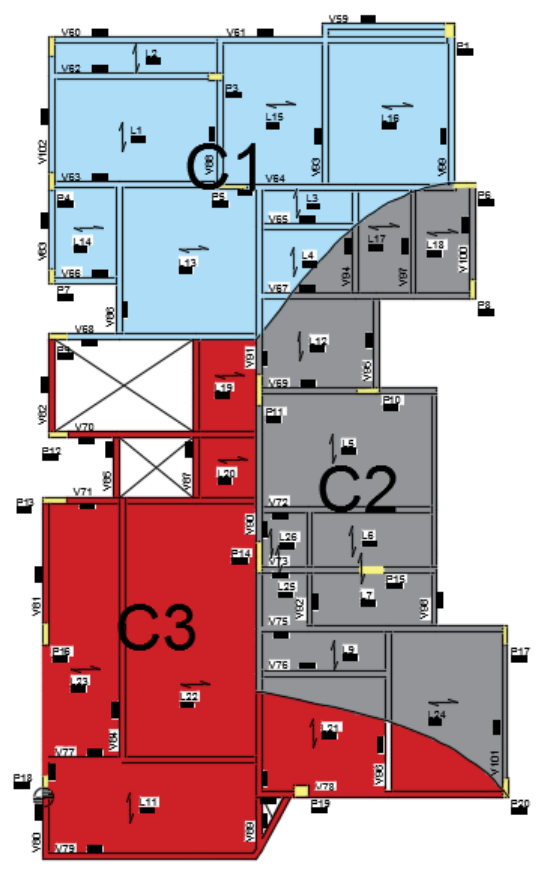

Figura 1 - Rastreabilidade

\section{Obra B}

Na Obra B foi acompanhada a concretagem da primeira laje, de um Edifício Comercial e Residencial de 5 pavimentos no dia 31/08/2018, sendo empregado o concreto fornecido pela empresa Y. Os dados coletados estão expostos na Tabela 2 e a rastreabilidade na Figura 2.

Tabela 2. Dados coletados da Obra B 


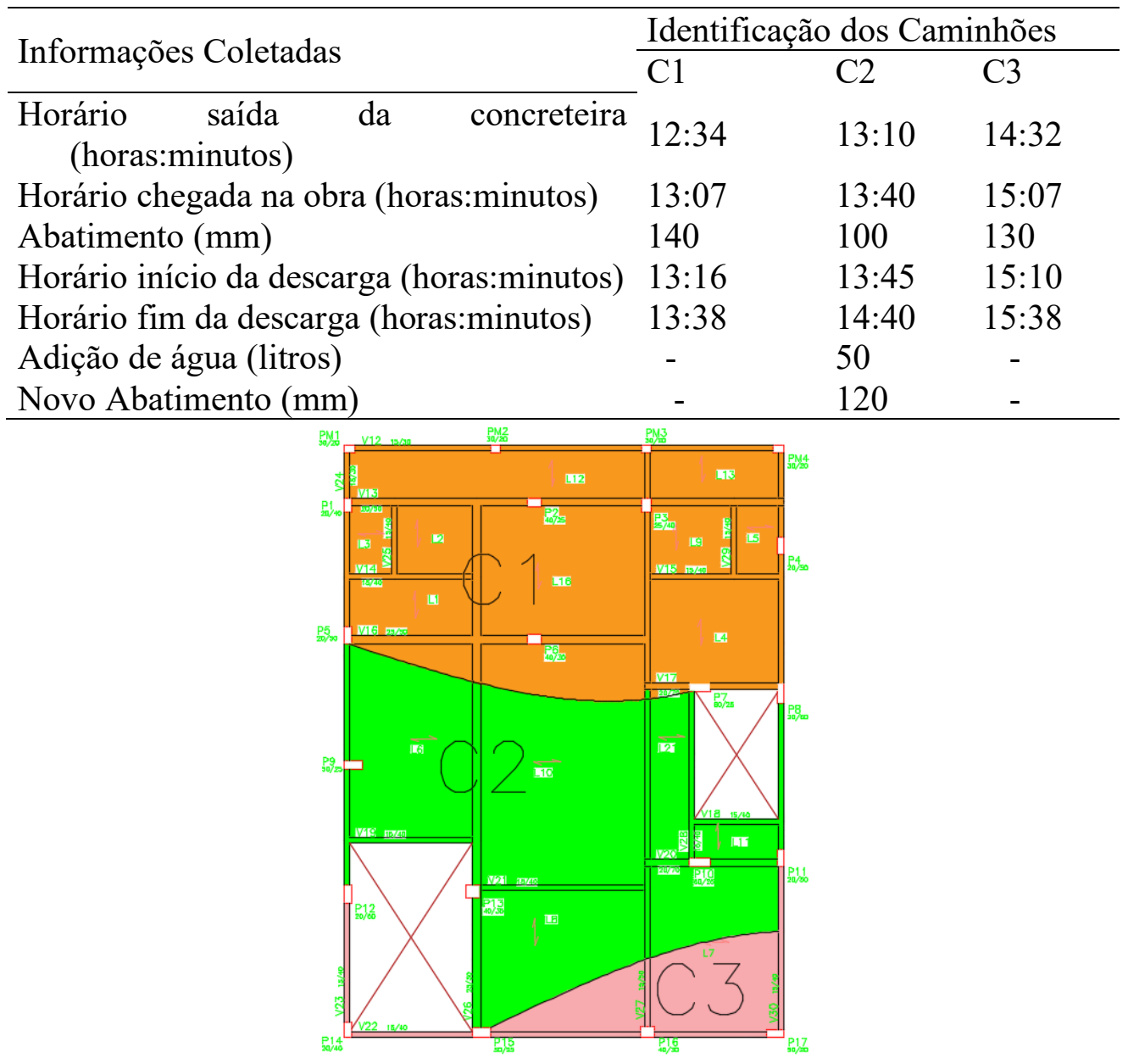

Figura 2 - Rastreabilidade

\section{Obra C}

Na obra C a concretagem acompanhada foi a da primeira laje de uma edificação residencial de 2 pavimentos, no dia 08/09/2018 sendo empregado o concreto fornecido pela Empresa Y. Os dados coletados podem ser verificados na Tabela 3 e a rastreabilidade na Figura 3.

Tabela 3. Dados Coletados na Obra C

\begin{tabular}{lll}
\hline \multirow{2}{*}{ Informações Coletadas } & \multicolumn{2}{l}{ Identificação do caminhão } \\
\cline { 2 - 3 } & C1 & C2 \\
\hline Horário saída da concreteira (horas:minutos) & $07: 02$ & $08: 45$ \\
Horário chegada na obra (horas:minutos) & $07: 28$ & $09: 05$ \\
Abatimento (mm) & 140 & 110 \\
Horário início da descarga (horas:minutos) & $07: 32$ & $09: 10$ \\
Horário fim da descarga (horas:minutos) & $08: 20$ & $10: 00$ \\
Adição de água (litros) & 75 & - \\
Novo Abatimento (mm) & 170 & - \\
\hline
\end{tabular}




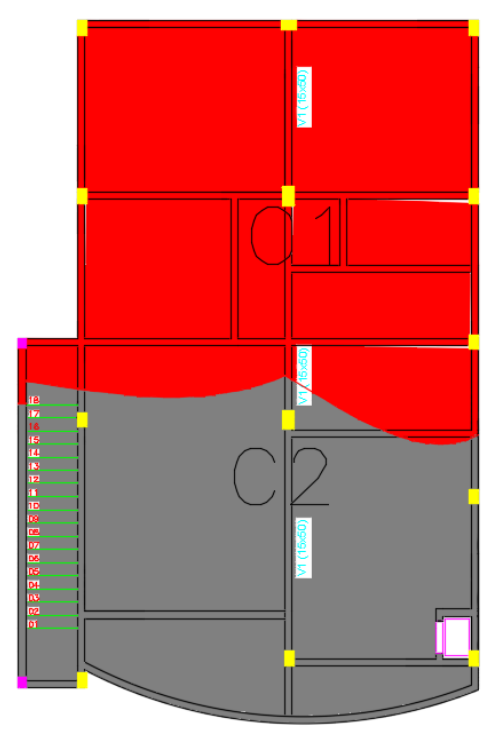

Figura 3 - Rastreabilidade

\section{Obra D}

A concretagem acompanhada foi a da sétima laje de um Edifício Residencial, no dia 12/09/2018, sendo o concreto empregado fornecido pela empresa Y, o qual, foi solicitado pelo construtor com $\mathrm{f}_{\mathrm{ck}}$ de $30 \mathrm{MPa}$ e abatimento de $140 \mathrm{~mm}( \pm 20)$. Os dados coletados durante o acompanhamento da concretagem estão expostos na Tabela 4 e a rastreabilidade na Figura 4.

Tabela 4. Dados Coletados da Obra D

\begin{tabular}{llllll}
\hline \multirow{2}{*}{ Dados } & \multicolumn{5}{l}{ Identificação dos Caminhões } \\
\cline { 2 - 6 } & C1 & C2 & C3 & C4 & C5 \\
\hline Horário saída da concreteira (horas:minutos) & $12: 49$ & $13: 59$ & $14: 37$ & $14: 47$ & $15: 36$ \\
Horário chegada na obra (horas:minutos) & $13: 09$ & $14: 18$ & $14: 50$ & $15: 15$ & $15: 55$ \\
Abatimento (mm) & 150 & 170 & 150 & 180 & 140 \\
Horário início da descarga (horas:minutos) & $13: 37$ & $14: 21$ & $15: 07$ & $15: 20$ & $15: 56$ \\
Horário fim da descarga (horas:minutos) & $14: 19$ & $14: 46$ & $08: 20$ & $15: 55$ & $16: 37$ \\
Adição de água (litros) & - & - & 75 & - & - \\
Novo Abatimento (mm) & - & - & 170 & - & - \\
\hline
\end{tabular}




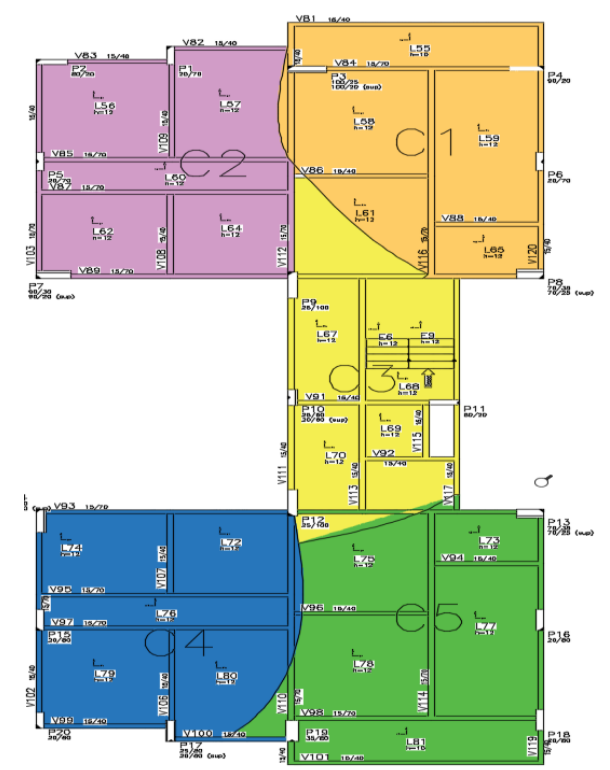

Figura 4 - Rastreabilidade

\subsection{Resultados dos ensaios de recebimento e aceitação do concreto}

\subsubsection{Ensaio de Consistência}

No Gráfico 1 são apresentados os valores resultantes da realização ensaio de abatimento de cone, seguindo as diretrizes da NM 16889:2020 para a aceitação do recebimento do concreto no estado fresco conforme determina a NBR 12655:2015.

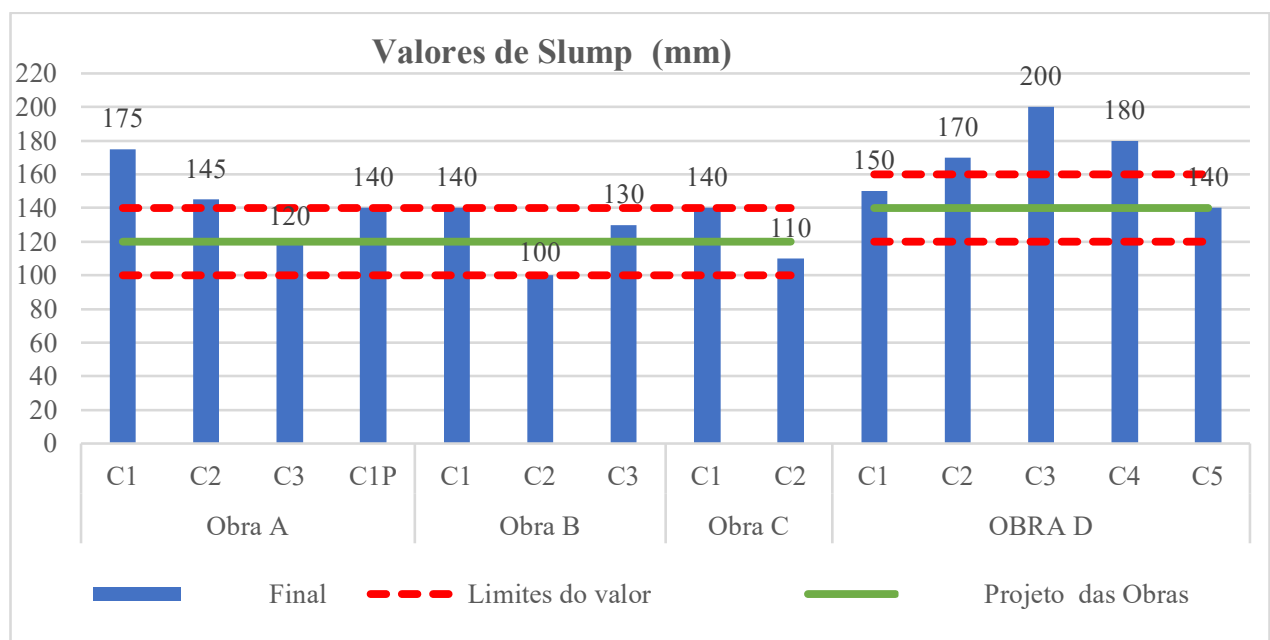

Gráfico 1 - Resultados obtidos com a realização do ensaio de abatimento de tronco de com (slump test)

Dentre as obras analisadas a única que especificou a consistência do concreto foi a obra $\mathrm{D}$, na qual o mesmo foi solicitado um abatimento de $140 \mathrm{~mm}( \pm 20 \mathrm{~mm})$. Nas demais a escolha do valor da consistência ficou a cargo das empresas fornecedores, sendo adotado por ambas o valor de 120 ( \pm $20 \mathrm{~mm})$.

Conforme pode ser verificado no Gráfico 1 os valores de abatimento dos caminhões $\mathrm{C} 3$ e $\mathrm{C} 1 \mathrm{P}$ da Obra A, todos os caminhões analisados na obra B e C e os caminhões $\mathrm{C} 1$ e $\mathrm{C} 5$ da obra 5 
encontravam-se dentro dos limites inferiores e superiores do abatimento de projeto e desta maneira conforme determina a NBR 12655:2015 poderiam ser aceitos.

Já os valores de abatimento dos caminhões C1 e C2 da Obra A, C2, C3 e C4 da Obra D, encontravam-se acima dos limites estabelecidos e de acordo com o estabelecido pela norma NBR 12655:2015 deveriam ter sido rejeitados. Nota-se desta maneira que a empresa Y mantem um maior controle na consistência dos concretos fornecidos.

\subsubsection{Ensaio de Resistência à Compressão Axial}

O Gráfico 2 demonstra os resultados das resistências característica à compressão estimada (fck,est) dos concretos curados em obra e em laboratório no Laboratório.

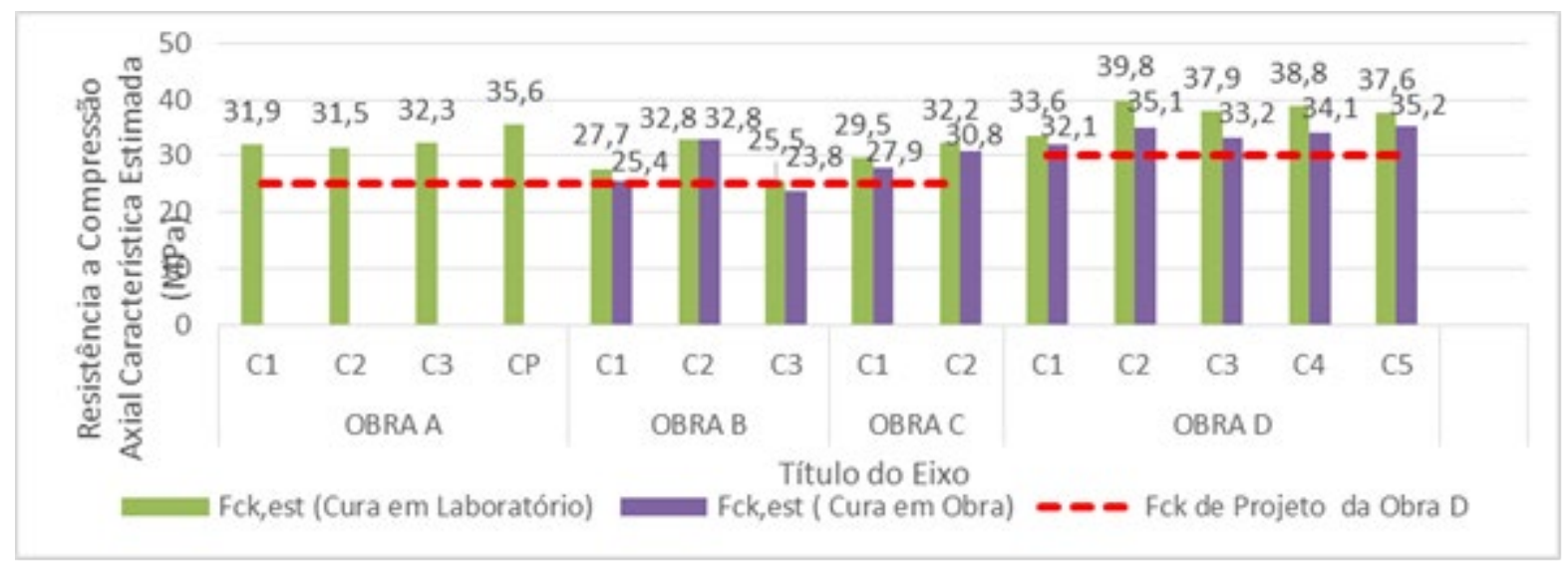

Gráfico 2 - Resistências característica à compressão estimada (fck,est)

A Obra A não apresenta resultados para a cura realizada em obra porque na data em que ocorreu a concretagem ainda não havia sido determinada a realização de tal procedimento.

A partir da análise dos resultados observou-se que todos os corpos de prova submetidos a cura em laboratório, apresentaram resultados satisfatórios atendendo ao Fck solicitado e desta maneira podendo ser aceitos conforme determinado pela NBR 12655:2015.

Resultados estes semelhantes aos encontrados nos estudos de casos realizados na cidade de Goiânia por Arantes e Vaz (2014) e Braz, Magalhães Filho e Zalaf (2014) onde todos os concretos empregados também obtiveram valores em conformidade com o fck de projeto. Já no trabalho realizado por Pedrosa (2016) para os concretos moldados in loco, 3 das 12 amostras apresentaram valores abaixo do Fck de projeto.

Os corpos de prova submetidos às mesmas condições de exposição e cura que os elementos concretados na obra, com exceção do Caminhão 1 da Obra $\mathrm{B}$, apresentaram uma queda média de $7,45 \%$ na sua resistência à compressão axial. Como consequência da diminuição dos valores de resistência, o Caminhão 3 da Obra $B$ apresentou o valor de $F_{\text {ck, est }}$ inferior ao de projeto. Desta maneira, destaca-se a importância não apenas da realização do controle de recebimento e aceitação do concreto nas obras, como do controle de qualidade do todo da obra, pois a cura inadequada pode resultar em um concreto com resistência à compressão axial desconforme.

\section{CONSIDERAÇÕES FINAIS}

Com a realização do presente trabalho verificou-se a ausência do atendimento a NBR 12655:2015 em todas as obras analisadas, demonstrando a realidade encontrada em grande parte das obras de pequeno e médio porte na cidade de Frederico Westphalen, onde a realização de ensaios para a verificação da qualidade do concreto fica restrita apenas as empresas fornecedoras de concreto. 
Notou-se também a desconformidade no valor de abatimento dos concretos fornecidos pela empresa $\mathrm{X}$, onde 4 dos 8 caminhões empregados nas obras apresentaram valor de abatimento superior ao de projeto e deveriam ter sido rejeitados. Já referente ao ensaio de resistência a compressão axial, todos os valores de $\mathrm{F}_{\mathrm{ck}}$, est dos concretos submetidos a cura em laboratório, seguindo as diretrizes da norma, obtiveram resultados satisfatórios atendendo ao $\mathrm{F}_{\mathrm{ck}}$ de projeto.

No entanto no comparativo entre os valores de $\mathrm{F}_{\mathrm{ck}}$, est corpos de prova curados em laboratório e os

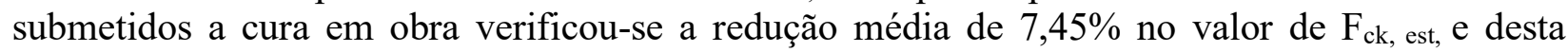
maneira o valor de $F_{c k}$, est do Caminhão 3 da Obra $B$ ficou abaixo do $F_{c k}$ de projeto.

Outro aspecto, observado em desconformidade com estabelecido pela norma NBR 12655:2015, foi a ausência de especificação por parte das obras nas características do concreto pois com exceção da Obra $\mathrm{D}$, as demais obras realizaram o pedido contemplando apenas o valor de $\mathrm{F}_{\text {ck. }}$.

Quanto as diretrizes estabelecidas pela NBR 7212:2012 verificou-se a ocorrência de adição suplementar não permitida em todas as obras, não sendo em nenhuma delas o procedimento anotado no documento de entrega pelos funcionários conforme determinado pela norma.

Observa-se, portanto, que o controle tecnológico na cidade de Frederico Westphalen tem apresentado resultados abaixo do esperado e determinado nas normas correspondentes, sendo negligenciado pelos profissionais responsáveis e consequentemente pelos proprietários das obras.

\section{REFERENCIAS}

ASSOCIAÇÃO BRASILEIRA DE NORMAS TÉCNICAS: NBR 12655: Concreto de Cimento Portland - Preparo, controle, recebimento e aceitação- Procedimento. Rio de Janeiro: 2015

. NBR NM 33/1998: Amostragem do Concreto Fresco. Rio de Janeiro, 1998.

. NBR NM 16889/2020: Concreto - Determinação da consistência pelo abatimento do tronco de cone. Rio de Janeiro, 2020.

. NBR 7212/2021: Execução de concreto dosado em central - - Preparo, fornecimento e controle. Rio de Janeiro, 2021.

. NBR 5738/2015: Concreto - Procedimento para moldagem e cura de corpos de prova. Rio de Janeiro, 2015.

. NBR 5739/2018: Concreto - Ensaio de compressão de corpos de prova cilíndricos. Rio de Janeiro, 2015.

2014.

NBR 6118/2014: Projeto de estruturas de concreto - Procedimento. Rio De Janeiro. RJ,

AMBROZEWICZ, P. H. L., Materiais de Construção. 1 Ed. São Paulo. PINI,2012.

ARANTES, G.M; VAZ, F.H.B. Controle e qualidade no recebimento de concreto dosado em central, 2014, 66f. Monografia (Engenharia Civil) - Universidade Federal de Goiás, Goiânia, 2014.

BRAZ, T.C; MAGALHÃES FILHO, S. R; ZALAF, R. S. Estudo do controle tecnológico e recebimento do concreto em obra, 2014, 91f. Monografia (Engenharia Civil) - Universidade Federal de Goiás, Goiânia, 2014. 
MARTINS, A. S. F. S; MAIA FILHO, H. M. Vetor. Verificação da Resistência do Concreto In Loco: Métodos de Ensaios Mais Usuais, Rio Grande, v 25, n 2, p 25-40,2015. Disponível em:< https://periodicos.furg.br/vetor/article/view/4794/4205. Acesso em 5 de abril de 2020.

MEHTA, P.K.; MONTEIRO, P.J.M. Concreto: Microestrutura, Propriedades e Materiais, São Paulo: IBRACON, 2ed, 2014, 782 p.

NEVILle, A. M; BROOKS, J.J. Propriedades do Concreto. 5. Ed. Porto Alegre: Bookmam, 2016.

PEDROSA, M. L. C. Controle de qualidade e rastreabilidade para concreto moldado in-loco para habitações de interesse social.2016, 74 f. Monografia (Engenharia Civil) - Universidade Federal de Ouro Preto, Ouro Preto, 2016. 